\title{
Enseñanza del inglés en secundaria: una propuesta innovadora
}

\author{
English Teaching at Secondary Education: An Innovative Proposal
}

\author{
Zayra Elisa Carvajal-Portuguez ${ }^{1}$ \\ Ministerio de Educación Pública \\ Cartago, Costa Rica \\ zcarvajalpotuguez@gmail.com
}

\begin{abstract}
Recibido:14 Agosto 2013 Aceptado: 29 julio 2013 Corregido: 29 octubre 2013
\end{abstract}
\begin{abstract}
Resumen: Este artículo desarrolla una propuesta innovadora para la enseñanza del inglés en secundaria, específicamente en el currículum operativo; es decir, el currículum que se lleva a cabo entre el docente y sus estudiantes en el aula. Dicha propuesta pretende lograr el alcance de los objetivos que han sido encomendados a las instituciones educativas, a las cuales se les ha dado la potestad de formar, capacitar, evaluar y preparar a los discentes de secundaria, esto con el fin de que el estudiantado aprenda el idioma inglés y posteriormente, logren comunicarse a través de este. La propuesta considera instrumentos necesarios en la enseñanza del idioma inglés, entre ellos se cuenta con el instrumento de valoración y los indicadores para determinar el nivel del estudiantado, así como planeamientos de actividades para ser utilizadas en las distintas destrezas de este idioma. Dichos instrumentos se presentan como aportes curriculares significativos para una futura implementación de la propuesta por parte del y la docente de la enseñanza del inglés, pues les proporciona la información necesaria para conocer y determinar el nivel en que se encuentra la competencia de cada estudiante, así como las actividades que puede realizar exitosamente para aumentar ese nivel. Es relevante indicar que los instrumentos exponen cuatro destrezas del idioma inglés: escuchar, leer, hablar y escribir; tal y como se plantea en el Programa de Estudio de la Enseñanza del Inglés Educación Diversificada del Ministerio de Educación Pública de Costa Rica.
\end{abstract}

Palabras clave: enseñanza del inglés, currículum operativo, escucha, habla, lectura y escritura.

Abstract: An innovative proposal is developed for teaching English at secondary education, specifically in the operative curriculum. That is, the curriculum that takes place between the teacher and their students in the classroom. Such proposal aims to reach the objectives that have already been assigned to schools at the secondary education. These schools have been given the power to shape, train, evaluate and instruct students, so that secondary education students really acquire the English language in such a way that they will have the capacity to communicate through the use of this language. This proposal takes into account the necessary instruments for teaching English; including assessment and its indicators to determine the level of proficiency each student has as well as the activities planned to develop the different skills in order to acquire this language. These instruments offer as significant curricular contributions for the implementation of this proposal by English teachers since it provides them with the necessary information to determine the student's level of English proficiency and the activities these teenagers can successfully perform in order to improve their level. It is relevant to highlight that those instruments develop four English language skills: listening,

$1 \quad$ Magíster en Planificación Curricular de la Universidad de Costa Rica. Actualmente labora como asesora nacional de Inglés en las oficinas centrales del Ministerio de Educación Pública, en la Dirección de Gestión y Evaluación de la Calidad. Dirección: Frente Mall Paraíso, Residencial Lánkaster II etapa, casa 20C, Cartago, Costa Rica. Teléfono: (506)+8318-2677. Correos electrónicos: carvajal26_04@yahoo.com, zcarvajalportuguez@gmail.com 
speaking, reading, and writing. As it is established in the English Syllabus by the Ministry of Public Education in Costa Rica.

Keywords: English teaching, operative curriculum, listening, speaking, reading, and writing.

\section{Introducción}

En la actualidad, en la mayoría de los campos laborales, existe una creciente demanda de profesionales con un alto dominio del idioma inglés, lo cual implica un mayor compromiso por parte de las instituciones educativas y sus actores, para formar ciudadanos competitivos en este aspecto. Es importante recalcar que la enseñanza en general es una tarea compleja en todo sentido; aún más el enseñar un idioma, por cuanto se debe enseñar a las personas a comunicarse de manera eficiente y eficaz, debido a que la comunicación es esencial para lograr relaciones interpersonales, así como poder acceder a todo tipo de conocimientos y producir nuevos saberes. Por tanto, si es desafiante enseñar una lengua materna, mucho mayor es el reto de enseñar una lengua extranjera.

La enseñanza de un idioma distinto al materno tiene varios inconvenientes, por lo que en ocasiones es rechazado ya sea por el estudiantado o por los padres y las madres de familia; en otras ocasiones no se cuenta con el material didáctico para la enseñanza y aprendizaje de esa nueva lengua, es por ello que su aprendizaje cuenta con un sin número de situaciones a la hora de aprenderlo.

El propósito de este artículo, es brindarle al docente novedosas herramientas que le permitan y faciliten llevar a cabo la enseñanza y aprendizaje del inglés a través de estrategias, métodos y técnicas en ese idioma. Cabe mencionar que los instrumentos expuestos en el artículo se toman del trabajo final de investigación aplicado llamado Lineamientos Curriculares en la Enseñanza del Inglés en Secundaria, basados en el Enfoque Comunicativo, realizado por la exponente de este artículo.

Para responder al propósito de este artículo se abordan dos temas principales: el relacionado con el currículum operativo y la enseñanza y aprendizaje del idioma inglés dentro de ese currículum.

\section{El currículum operativo}

Según aportes dados por Gimeno (2007) y Posner (2004), un currículum oficial cobra sentido hasta el momento en que las profesoras y los profesores lo traducen a un currículum operativo.

En palabras del mismo Posner (2004), este asevera que “[...] el currículum operativo consiste en lo que el profesor realmente enseña y cómo comunica su importancia al estudiante es decir, cómo sabe el estudiantado que es importante [...] El currículo operativo tiene dos aspectos: 1) el contenido incluido y el énfasis que le da el profesor en clase, por ejemplo, lo que realmente enseña, y 2) los resultados del aprendizaje o los estándares que son responsabilidad del estudiantado, es decir, lo importante" p.13. 
Por tanto, el primer aspecto se muestra según el tiempo que le dedica el profesor o la profesora a cada tema y al tipo de aprendizaje que lleve a cabo; el segundo aspecto se ve reflejado en el momento en que se evalúa lo enseñado; es decir, el currículum evaluado.

Por su parte, Gimeno (2010), indica "[...] lo que enseña el profesorado es el resultado de un proceso de decodificación -interpretación, significación, recreación, reinterpretación...- de ideas, condiciones y prácticas disponibles en la cultura, que se hacen más o menos visibles y viables en un contexto situacional de interacción e intercambio de significados" p.223.

De tal manera, en la práctica, o lo que en palabras de Gimeno (2007), es llamado el currículum en acción, es el momento donde toda propuesta, intención, teoría, etc., cobra vida y sentido tanto para el o la docente como para los alumnos y las alumnas.

Por otro lado, tras los aportes de Posner (2004); Gimeno y otros (2010), dentro del currículum operativo se encuentran grandes ejes que lo delimitan, los cuales Marsh citado por Escudero (1999), los define como "[...] un conjunto interrelacionado de planes y experiencias que los alumnos siguen bajo la guía de la escuela" p.34. Según este planteamiento, el o la docente podrá emplear los lineamientos que les sirvan de guía en su rutina de trabajo con sus alumnos, los que más tarde le permitirán analizar su lección, si así lo desea.

Entre los ejes del currículum, Escudero (1999) ratifica

En uno de ellos se puede contemplar los contenidos (productos) y los procesos; en el otro, la dimensión de planes como resultados intencionales del aprendizaje (objetivos o metas), o las experiencias vividas en el aula. El primero delimita los fines (planes o contenidos), el segundo, la dimensión, los medios, entendidos aquí como el conjunto de oportunidades de aprendizaje que la escuela ofrece, o los procesos que pone en juego p.34.

Además de los elementos antes mencionados, está lo que se quiere enseñar o aprender (contenidos curriculares) y los procedimientos o instrumentos para enseñarlo o aprenderlo (medios). Por tal motivo, el propósito de enseñar un contenido es conseguir alguna meta (objetivos), cuando se realiza el acto de enseñar y aprender, se suscita en una situación determinada por condiciones físicas, sociales y culturales (contexto).

Tal como lo menciona Hernández (1998), “[...] enseñar es el acto por el que un profesor (educador), muestra o suscita contenidos educativos (conocimientos, hábitos, y habilidades) a un alumno, a través de unos medios, en función de unos objetivos y dentro de un contexto" p.6. De acuerdo con lo anterior, los ejes del currículum operativo forman parte del espacio curricular que se lleva a cabo en la institución. Esto, por cuanto el currículum comprende tanto los planes como toda aquella experiencia que ocurre a través del camino que se recorre al poner en práctica el currículum.

Al tomar en cuenta que el currículum operativo es donde se lleva a cabo la práctica (acción), se hace necesario comprender los procesos de enseñanza y aprendizaje en ese currículum, específicamente en el idioma inglés. 


\section{Currículum operativo en la enseñanza y aprendizaje del idioma inglés}

\section{1. ¿Qué se entiende por enseñanza y aprendizaje?}

Al hablar de enseñanza y aprendizaje, se hace alusión a lo que según Brown (1994) es "[...] la adquisición u obtención de un conocimiento o habilidad que puede darse por el estudio, la experiencia o por la instrucción. El aprendizaje es un cambio permanente en el comportamiento y es el resultado de la práctica reforzada" p. 7.

Del mismo modo, Harmer (2007) menciona que cualquiera que sea el nivel del estudiantado y a pesar de que la organización en el estudio del lenguaje no sea en secuencias de enseñanza, hay cuatro cosas que las y los discentes tienen que hacer con el "nuevo" lenguaje: estar expuestos a él, entender su significado, entender su forma (cómo se construye) y practicarlo, de esta forma se expondrán al dominio expresivo y comprensivo de los mecanismos verbales y no verbales de comunicación y representación, que constituyen la base de toda la interacción social y por ende, de todo aprendizaje. Aunado a ello, se menciona que la enseñanza está implícita en el aprendizaje, esta enseñanza va a ser la demostración o ayuda que se le brinda al aprendiz para que conozca o aprenda a través de instrucciones, de una guía, y ofreciéndole el conocimiento.

\section{2. ¿Cómo se aprende y cómo se enseña un idioma?}

De acuerdo con Bello (1990), "[...] el niño empieza a aprender de otros niños y de los adultos, de los medios de comunicación, y hacia los 5-7 años ya son capaces de hablar casi perfectamente” p.14. Según Brown (1994) “[...] en el primer año, el bebé solamente es capaz de imitar sonidos o palabras, que el niño o la niña escucha en el entorno; sin embargo, ya cuando el niño cuenta con unos 18 meses, esas palabras se han multiplicado considerablemente" p.21.

Por su parte, Mackey (1969), "[...] menciona que en el campo de la enseñanza de un idioma, se dice que la niñez ha sido llamada la edad de la formación" p.121. Esto porque las niñas y los niños aprenden la estructura de un idioma, sin siquiera saber qué es lo que están diciendo. Por el contrario, la persona adulta sí pretende entenderlo y encuentra que la nueva estructura no tiene la misma organización cuando pretende usar el nuevo vocabulario para decir lo que quiere.

Igualmente, Harmer (2007) indica que la edad de los discentes es un factor importante en las decisiones de las profesoras y los profesores acerca de cómo y qué enseñar. Las personas de diferentes edades tienen distintas necesidades, competencias y habilidades cognitivas. Se espera que los niños y las niñas en la edad de primaria adquieran gran parte de la lengua extranjera a través del juego, por ejemplo, mientras que para los adultos se puede razonablemente esperar un mayor uso del pensamiento abstracto.

No obstante, no solo la edad es relevante a la hora de aprender un idioma, ya que para Harmer (2011) "[...] el estudiante es un individuo con distintas experiencias, tanto dentro como fuera del aula. Los comentarios que se hacen acerca de los niños y las niñas, los y las adolescentes y los adultos sólo son generalizaciones. Mucho depende también de las 
diferencias individuales de las y los educandos y de la motivación con que cuenten a la hora de aprender" p.37.

Para Harmer (2011), en el caso de las niñas y los niños pequeños, especialmente en edades de nueve o diez años, aprenden de las siguientes formas: responden las preguntas que se les haga, incluso si no entienden las palabras individualmente. A menudo aprenden indirectamente, es decir que toman la información de todos los lados, aprendiendo de todo lo que les rodea en lugar de centrarse solo en el tema que se les enseña. Su aprendizaje no viene solo de la explicación que reciben, sino también de lo que ven y oyen, esto porque tienen la oportunidad de tocar e interactuar con ello. Además, los niños y las niñas están dispuestos a hablar de sí mismos y responder así al aprendizaje cuando utiliza sus propias vidas como temas principales.

En cuanto al aprendizaje de un idioma en una persona adulta, Pinker (citado por Harmer, 2011), asegura que "[...] los adultos a menudo dependen del ejercicio considerable de sus intelectos, a diferencia de los niños y las niñas en quienes la adquisición del lenguaje ocurre de manera natural". Al respecto, Harmer (2011), plantea que "[...] los adultos tienen expectativas sobre el proceso de aprendizaje y puede que ya tengan sus propios patrones del sistema" p.38. Los adultos llegan a las aulas, con grados de experiencias que permiten a las y los docentes utilizar una amplia gama de actividades con ellos. También, los adultos tienden, en general, a ser más disciplinados que algunos niños, niñas y adolescentes y lo más importante, a menudo se encuentran dispuestos a luchar y superar obstáculos. A diferencia de las niñas y los niños pequeños y los adolescentes, que a menudo se preguntan por qué están aprendiendo y lo que quieren es salir del aula.

Por otro lado, durante muchos años la enseñanza de un idioma extranjero ha resultado ser una actividad importante para profesoras y profesores, alumnos, militares y lingüistas, entre otros. El interés en el aprendizaje de otros idiomas se ha centrado básicamente en tres niveles; en el nivel comercial, económico y político, esto por motivo del desarrollo y aplicación de diferentes métodos, además de necesidades de cambio a nivel social o personal del estudiantado. La insuficiencia de comunicación con los habitantes de cualquier parte del mundo, ha provocado el desarrollo de estrategias para alcanzar tales fines. Seguidamente, se describen algunos elementos ineludibles en el aprendizaje de un idioma.

\section{3. ¿Qué elementos son necesarios para el aprendizaje de idiomas con éxito en un salón de clases?}

De acuerdo con Harmer (2007), las alumnas y los alumnos en el aula por lo general no reciben el mismo tipo de exposición o el estímulo que los que -a cualquier edad- se encuentran fuera de ella "exponiéndose" al idioma. Pero eso no significa que los que se encuentran dentro de un aula, no puedan aprender un idioma si se dan las condiciones adecuadas, como la motivación, la exposición a la lengua, y las posibilidades de utilizar el lenguaje.

En consecuencia, los elementos que de acuerdo con Harmer (2007) deben estar presentes en una clase, para que los alumnos aprendan más y mejor, se les denomina ESA, según sus siglas en inglés (Engage/Vincular, Study/Estudiar, Activate/Activar). 
Vincular: este es el punto de una secuencia de enseñanza en donde los maestros y las maestras tratan de despertar el interés del estudiantado, con la participación de sus emociones. Las actividades y materiales que con frecuencia involucran al estudiantado son juegos (dependiendo de la edad y tipo), música, debates, imágenes estimulantes, sus historias y anécdotas divertidas.

Estudiar: las actividades de estudio son aquellas en las que se le pide al discente centrarse en el idioma (o en la información dada) y cómo esta se construye. El estudiantado puede estudiar en una variedad de diferentes estilos, estudiar la evidencia del lenguaje para descubrir la gramática por sí mismos, trabajar en grupos que estudian un texto o el vocabulario de una lectura y el profesor y la profesora pueden explicarles la gramática. Pero sea cual sea el estilo, el estudio será cualquier escenario en el que la construcción del lenguaje es el foco principal.

Activar: este elemento describe ejercicios y actividades que se han diseñado para que los discentes que utilizan el lenguaje en forma libre y "comunicativa" lo utilicen tanto como ellos puedan. El objetivo del estudiantado no es centrarse en la construcción del lenguaje y prácticas específicas del lenguaje (patrones de gramática, vocabulario en particular o funciones), pero sí los puede utilizar siempre que sean apropiados para una situación o un tema determinado.

Por otra parte, además de los elementos antes señalados, es necesario contar con algunas de las estrategias de aprendizaje que pueden llevarse a cabo en la clase, para el desarrollo de la comunicación oral en un idioma extranjero; de acuerdo con Celce-Murcia (1991), algunas de esas estrategias de aprendizaje, son las actividades de estructura lingüística, actividades de ejecución, las actividades de participación y las actividades de observación.

Según la misma autora, en cuanto a las actividades de estructura lingüística se puede mencionar la entrevista estructurada, donde los educandos se hacen preguntas uno al otro y se contestan utilizando el idioma inglés, así intercambian información real y al mismo tiempo repiten y refuerzan estructuras específicas. Las actividades de ejecución se refieren a las que el estudiantado le brinda información específica al resto de compañeros, por ejemplo las presentaciones orales. Las actividades de participación son aquellas en donde el o la estudiante participa en una actividad oral en un escenario natural, por ejemplo grabar una conversación espontánea con un hablante nativo. Por último, están las actividades de observación, estas son actividades en las cuales un estudiante observa o graba una conversación entre dos o más hablantes nativos en su idioma materno.

Conjuntamente, las actividades que se recomiendan en esta propuesta pretenden lograr el alcance de los objetivos que han sido encomendados a las instituciones educativas, esto con el fin de que el estudiantado aprenda el idioma inglés y posteriormente, logre comunicarse a través de este. Las actividades propuestas están basadas en las cuatro habilidades del idioma inglés: escuchar, leer, hablar y escribir; tal y como se plantea en el Programa de Estudio de la Enseñanza del Inglés de la Educación diversificada del Ministerio de Educación Pública de Costa Rica, sin ninguna subdivisión dentro de las mismas. 
En cuanto a las cuatro habilidades del inglés escuchar, leer, hablar y escribir, Harmer (2011) las señala de la siguiente manera:

\section{Escuchar:}

La escucha debe ser de manera extensa e intensa, ya que de esa manera el estudiantado puede mejorar sus habilidades y obtener valiosa información del lenguaje a través de una combinación de materiales y procedimientos de escucha extensiva e intensiva.

Del mismo modo que, la lectura extensiva ayuda al estudiantado a adquirir el vocabulario y la gramática y además hace que los discentes sean mejores lectores, la escucha extensa también puede tener un resultado positivo en el aprendizaje del idioma de un o una estudiante, debido a que esta se refiere generalmente a la escucha fuera del aula; es decir, en el hogar, el autobús, o en equipos de música personales a medida que viajan de un lugar a otro. Por otro lado, se menciona la escucha intensa como a la escucha en vivo, esta es una forma popular de asegurar una comunicación genuina, por ejemplo, cuando se presenta el caso donde el profesor, la profesora y visitantes charlan en la clase con las y los educandos.

En cuanto a los materiales que se utilizan para una escucha extensa se pueden encontrar a partir de un sinnúmero de fuentes; no obstante, a pesar de la variedad de materiales innovadores y los avances en la tecnología en cuanto a los mismos, el autor argumenta que muchos profesores y profesoras utilizan material grabado y cada vez es más importante, ya que este estará disponible cuando se requiere que el estudiantado practique habilidades. Asimismo, este tiene sus ventajas y desventajas:

Ventajas: el material grabado permite que el estudiantado escuche una variedad de voces diferentes. Les da la oportunidad de conocer una variedad de personajes, sobre todo cuando se trata de grabaciones con personas reales que son las que están hablando. El material grabado es extremadamente portátil y de fácil acceso, también son baratos.

Desventajas: en grandes aulas con mala acústica, la audibilidad del material grabado es motivo de preocupación. A menudo es difícil asegurar que todo el estudiantado en una misma habitación puede oír igualmente bien. Otro problema con los audios en el aula es que todos tienen que escuchar a la misma velocidad, una velocidad determinada por la cinta, no por los oyentes.

En cuanto al papel del profesor y la profesora, el autor indica que en todas las actividades de escucha lo que se necesita es crear la participación de las y los educandos a través de tareas establecidas, se enfatiza que se debe construir confianza en el estudiantado, ayudándoles a escuchar mejor y no poniendo a prueba sus habilidades.

\section{Leer:}

Igualmente que para Harmer (2011), la escucha debe ser extensa e intensa, así debe ser también la lectura, esto debido a que a través de la misma se puede obtener el máximo beneficio.

Para lograr una lectura extensa exitosa, una de las condiciones fundamentales es que 
el estudiantado pueda comprenderla. Si ellos están luchando para entender cada palabra, difícilmente puedan leer por placer, el cual es el objetivo principal de esta actividad. Esto significa que se debe proporcionar libros que sean de fácil acceso para las y los discentes y con un vocabulario adecuado.

Con el fin de lograr que las y los educandos lean con entusiasmo en la clase, se tiene que trabajar para crear interés en el tema y en las tareas. Sin embargo, hay otros papeles que tienen que adoptar las y los docentes cuando se le pide al estudiantado leer intensamente, por ejemplo, decirles exactamente cuál es el propósito de la lectura, darles instrucciones claras sobre la forma de lograrlo y el tiempo que tienen para hacerlo.

Sobre los efectos de introducir pronto la lectura en la enseñanza de una lengua extranjera, incluso en niñas o niños pequeños, Dlugosz (2000), señala "[...] la introducción temprana a la lectura acelera, por añadidura sus progresos en entender y hablar la lengua extranjera" p.286.

En la propuesta de Dlugosz (2000) para la lectura de los niños y las niñas se insiste en que "[...] cada palabra, presentada individualmente por medio de tarjetas, o cada frase, vaya siempre acompañada de la lectura repetida en voz alta hecha por el profesor" p.286. Asimismo la autora expone que dentro de los factores de lectura que resultan beneficiosos en el proceso de adquisición; uno de ello es que "[...] al presentar una palabra o frase en sus formas fónica y gráfica se activan dos canales de percepción -auditiva y visual- los cuales ayudan a acelerar el aprendizaje, al producirse así mas asociaciones facilita su almacenaje en la memoria" p.286.

Hablar:

Para Harmer (2011), la capacidad de hablar con fluidez presupone no sólo el conocimiento de las características del lenguaje, sino también la capacidad para procesar información y lenguaje "en el acto".

Entre los elementos necesarios para la producción oral, el autor afirma que los hablantes eficaces de inglés necesitan ser, no solamente capaces de producir fonemas individualmente, sino además usarlos con fluidez, es por eso que se debe involucrar al estudiantado en actividades que ayuden a mejorar el hablar. Al respecto Celce-Murcia (1991) expone que "[...] el objetivo del componente del habla en una clase de idiomas debe ser la adquisición de la habilidad de la comunicación oral real tanto dentro como fuera de la clase" p.126.

$\mathrm{Al}$ igual que con cualquier otro procedimiento de aula, las profesoras y los profesores tienen que desempeñar una serie de funciones diferentes. Sin embargo, tres de ellas tienen especial interés cuando estamos tratando de lograr que las y los discentes hablen con fluidez, estos son:

Facilitador: el estudiantado a veces se pierde, no pueden pensar en qué decir a continuación, de alguna u otra manera pierden la fluidez que se espera de ellos. Se puede trabajar con ellos para evitar este tipo de situaciones, pero también es posible que podamos ayudarles ofreciéndoles sugerencias discretas. 
Participante: el profesor y la profesora deberían ser buenos animadores para lograr producir el lenguaje. A veces esto se puede lograr mediante la creación de una actividad y con mucho entusiasmo.

Retroalimentador: la controvertida cuestión de cuándo y cómo dar retroalimentación en actividades en donde el objetivo es lograr que el estudiantado hable, es contestada por considerar cuidadosamente el efecto de la misma.

\section{Escribir:}

Harmer (2011) expone que el texto escrito tiene una serie de diferencias que lo separan del habla. Aparte de las diferencias en la gramática y el vocabulario, hay cuestiones de letra, palabra, y la formación de texto, que se manifiesta en la escritura, la ortografía, el diseño y la puntuación.

En ocasiones muchos discentes cuya ortografía de la lengua materna es muy diferente de la del inglés tienen muchas dificultades para formar las letras inglesas. A pesar de las faltas de ortografía no se suele impedir la comprensión de un mensaje escrito, que puede afectar negativamente a juicio del lector. Una de las razones por las que la ortografía es difícil para el estudiantado de inglés, se debe a que la correspondencia entre el sonido de una palabra y la forma en que se escribe, no es siempre evidente.

Existen diferentes técnicas para la práctica de la escritura, tanto dentro como fuera del aula. Por tanto, se debe elegir entre ellos al decidir si el objetivo es que las y los educandos se centren más en el proceso escrito o en su producto.

Si lo que se desea es una escritura creativa, el autor sugiere tareas creativas como escribir poesía, cuentos y juegos. Estas actividades tienen una serie de características, la principal de ellas es que el resultado final, a menudo se siente como una especie de logro y la mayoría de las personas, se sienten orgullosas de su trabajo y quieren que sea leído.

\section{Instrumentos de la propuesta a los y a las docentes.}

La propuesta a los y a las docentes se realiza una vez completada la investigación llamada Lineamientos Curriculares en la enseñanza de inglés en secundaria, basados en el Enfoque Comunicativo, la misma tiene como propósito brindar lineamientos curriculares a los y a las docentes de secundaria, para que desarrollen el enfoque comunicativo en sus clases.

Como parte de la viabilidad de la misma, se expone el tipo de investigación que se realizó, la población de estudio con la cual previamente se validaron los instrumentos, la selección de la muestra, el objetivo general y los objetivos específicos.

Tipo de investigación

La investigación inició en el año 2009 y se concluyó en el año 2011. En ella se utilizó tanto el método cualitativo como el método cuantitativo. Los cuales de acuerdo con Cook 1997, "[...] estos se refieren a las técnicas experimentales, tests "objetivos" de lápiz y 
papel, análisis estadístico multivariados, estudios de muestras, etc. En contraste, y entre los métodos cualitativos, figuran la etnografía, los estudios de caso, las entrevistas en profundidad y la observación participativa" pág.25. Esto por cuanto se consideró que, el utilizar los dos métodos complementaría la información requerida para dar respuesta al problema y a los objetivos de la investigación.

Además, fue una investigación cuantitativa inferencial con una evaluación directa mediante entrevista personal cara a cara, pues lo que se buscó fue hallar estadísticamente el factor real del nivel de inglés de los estudiantes de undécimo año en secundaria y a partir de cuáles actividades es que ellos logran obtener ese nivel. Para ello fue importante determinar la población de estudio.

Población de estudio

Se contó con dos poblaciones de estudio, el estudiantado y las y los docentes de undécimo año de secundaria, de colegios públicos académico-diurnos, rurales y urbanos de las provincias de Alajuela, Heredia, Cartago y San José. Las edades de las y los estudiantes oscilaron entre los 16 y 19 años.

Estimación del tamaño de muestra

El tamaño de muestra en la investigación fue de 240 estudiantes de undécimo año de secundaria, para lo cual se tuvo un error de muestreo del $6.5 \%$ con un nivel de confianza del 95\%. Por otro lado, la cantidad de profesores participantes de la muestra fue de 21.

Selección de la muestra

Para la selección de la muestra se tomaron aleatoriamente colegios públicos académicodiurnos tanto de zona urbana como rural, de las provincias de Alajuela, Heredia, Cartago y San José quedando representadas todas las zonas geográficas de interés.

Objetivo General:

Proponer lineamientos curriculares basados en el enfoque comunicativo para la enseñanza del inglés en secundaria, a partir del resultado del diagnóstico.

Objetivos Específicos:

1. Identificar en el Currículum prescrito (Programa de Estudios del M.E.P) y en el Currículum operacional (el aula) los componentes del enfoque comunicativo.

2. Determinar el desarrollo de las destrezas (escuchar, hablar, leer, escribir) en la enseñanza del inglés, mediante la medición de los componentes básicos (pronunciación, vocabulario, estrategias de comunicación, gramática) del enfoque comunicativo.

3. Tipificar el nivel real del conocimiento de inglés y las actividades de aprendizaje que se vinculan con dicho nivel, en estudiantes de undécimo año de secundaria.

Como parte de los instrumentos creados para los y las docentes de secundaria, se 
encuentra el "Instrumento de valoración de inglés". Este instrumento fue validado por 30 estudiantes de undécimo año escogidos al azar.

Se le pidió al estudiantado, que se auto-evaluara a través del instrumento de valoración de inglés, en el cual se encuentran algunas estrategias de comunicación, pronunciación, gramática y vocabulario, los cuales se valoraban con una escala, en donde valores muy bajos (0 y 1) y bajos (2, 3 y 4), significaban conocimiento bajo en inglés; niveles intermedios (5 y 6) un conocimiento medio, los valores altos ( 7 y 8 ) y muy altos (9 y 10), significaban altos conocimientos del idioma inglés.

Una vez que el estudiantado auto-evaluó su nivel de inglés en cada uno de los componentes de manera individual, sin ninguna intervención, se procedió a entrevistarlos cara a cara a través de una serie de preguntas abiertas. Cuando se terminaron las entrevistas de los y las discentes, se procedió a insertar los datos al paquete estadístico SPSS. Una vez insertados los datos en el paquete estadístico, este tomaba la nota puesta por el o la estudiante y la puesta por la entrevistadora para calcular el factor real de inglés de cada estudiante.

El factor real del nivel de inglés del estudiantado se calculó por medio del cociente, el cual se refiere a la división entre la calificación dada por la autora y la auto-evaluación del estudiantado. Este cálculo del factor real del nivel de inglés, sirvió para calcular posteriormente el nivel real de inglés de la muestra de 240 estudiantes.

Posteriormente, la autora utilizó otro instrumento "Indicador para determinar nivel de inglés de los estudiantes", el cual fue igualmente validado por algunos docentes y estudiantes seleccionados en la muestra.

En este instrumento se procede a introducir el dato que se obtiene como nivel real de inglés de los y las discentes, se insertan los datos en cada una de las pestañas disponibles, al finalizar, el instrumento da a conocer el nivel de inglés en que se encuentra el estudiantado; además, el instrumento ofrece información al docente respecto a la posición en que se encuentra el o la estudiante, esto de acuerdo a los colores del "semáforo", tomado en cuenta la escala de 0 a 10 en donde los valores muy bajos (0 y 1), los bajos (2, 3 y 4) son de color rojo, niveles intermedios ( 5 y 6 ) son de color amarillo, los valores altos (7 y 8 ) y muy altos (9 y 10) son de color verde.

Cuando ya se conoce el nivel de inglés de cada estudiante y del grupo en general, se planean las actividades a llevar a cabo con el estudiantado, los planeamientos que se le exponen a el o la docente cuentan con objetivos, actividades, tiempo aproximado de duración y evaluación; esto con el fin de que el o la docente lo utilice durante todo el año, según el tema que se esté desarrollando.

\section{Propuesta a los y a las docentes de inglés en secundaria.}

¿De qué trata la propuesta? Esta propuesta plantea las experiencias o actividades de aprendizaje que se sugiere lleven a cabo las y los docentes con el estudiantado de secundaria. 
De acuerdo con Garibay (2002), "la experiencia es el presenciar o sentir una cosa por sí mismo. La circunstancia de haber hecho repetida o duraderamente una cosa, es lo que da la habilidad para hacerla" p.06.

Por tanto, en esta propuesta se encuentran las experiencias o actividades de aprendizaje sugeridas para ser llevadas a cabo dentro o fuera del aula. Además, se ofrece a las y los docentes en la enseñanza y aprendizaje del idioma inglés, instrumentos que permitan autoevaluar al estudiantado su nivel en esta lengua; así como conocer el nivel real de inglés de los discentes y, a través de cuáles actividades puedan mejorar o mantener el nivel del idioma.

Por último, se le presenta a las y los docentes un planeamiento en cada una de las habilidades (listening, speaking, reading y writing) con objetivos, actividades, tiempo probable de duración y evaluación, el cual pueden utilizar en el aula para llevar a cabo las actividades que le ayudarán a mejorar el nivel de inglés del estudiantado; se aclara que las actividades sugeridas son para realizarse durante todo el año con los objetivos del programa que así lo permitan.

De acuerdo con autores tales como Celce-Murcia (1991); Littlewood (1992); Mackey (1969); Brown (1994) y Brumfit (1987), entre las actividades que pueden ser llevadas a cabo en el aula por parte de las y los docentes y el estudiantado de secundaria, se encuentran los ejercicios de gramática, ejercicios de listening, ejercicios de pronunciación, representación oral de diálogos y otras situaciones, role-plays, dictados, historias predecibles, debates, realizar una lectura y hacer preguntas abiertas; entre otras.

Es importante aclarar que no se sugieren solamente experiencias de aprendizaje que se puedan llevar a cabo dentro del aula, sino también aquellas que se pueden realizar fuera de ella y que, a su vez, se puedan evaluar dentro del aula.

\subsection{Instrumento para diagnosticar el nivel de inglés de los estudiantes en la enseñanza del inglés en secundaria}

Antes de iniciar con las actividades que ayudarán a las y los docentes a mejorar el nivel de inglés del estudiantado, es necesario que el o la docente conozca en qué nivel se encuentra cada uno de las y los educandos o si lo desea, el grupo en general, para ello el o la docente le facilitará a cada uno de los estudiantes, un "instrumento de valoración de inglés" 
Tabla No. 1. Instrumento de Valoración de Inglés

\begin{tabular}{|c|c|c|c|c|c|c|c|c|c|c|c|c|}
\hline \multicolumn{2}{|c|}{ Estrategias de comunicación } & \multicolumn{2}{|c|}{$\begin{array}{l}\text { MUY } \\
\text { BAJO }\end{array}$} & \multicolumn{3}{|c|}{ BAJO } & \multicolumn{2}{|c|}{$\begin{array}{l}\text { INTER- } \\
\text { MEDIO }\end{array}$} & \multicolumn{2}{|c|}{ ALTO } & \multicolumn{2}{|c|}{$\begin{array}{l}\text { MUY } \\
\text { ALTO }\end{array}$} \\
\hline 1 & Contacto visual & 0 & 1 & 2 & 3 & 4 & 5 & 6 & 7 & 8 & 9 & 10 \\
\hline 2 & Lenguaje corporal & 0 & 1 & 2 & 3 & 4 & 5 & 6 & 7 & 8 & 9 & 10 \\
\hline 3 & Gestos & 0 & 1 & 2 & 3 & 4 & 5 & 6 & 7 & 8 & 9 & 10 \\
\hline 4 & Monitoreo & 0 & 1 & 2 & 3 & 4 & 5 & 6 & 7 & 8 & 9 & 10 \\
\hline \multicolumn{2}{|c|}{ Pronunciación } & \multicolumn{2}{|c|}{$\begin{array}{l}\text { MUY } \\
\text { BAJO }\end{array}$} & \multicolumn{3}{|c|}{ BAJO } & \multicolumn{2}{|c|}{$\begin{array}{l}\text { INTER- } \\
\text { MEDIO }\end{array}$} & \multicolumn{2}{|c|}{ ALTO } & \multicolumn{2}{|c|}{$\begin{array}{l}\text { MUY } \\
\text { ALTO }\end{array}$} \\
\hline 5 & Consonantes & 0 & 1 & 2 & 3 & 4 & 5 & 6 & 7 & 8 & 9 & 10 \\
\hline 6 & Vocales & 0 & 1 & 2 & 3 & 4 & 5 & 6 & 7 & 8 & 9 & 10 \\
\hline 7 & Entonación & 0 & 1 & 2 & 3 & 4 & 5 & 6 & 7 & 8 & 9 & 10 \\
\hline \multicolumn{2}{|c|}{ Gramática } & \multicolumn{2}{|c|}{$\begin{array}{l}\text { MUY } \\
\text { BAJO }\end{array}$} & \multicolumn{3}{|c|}{ BAJO } & \multicolumn{2}{|c|}{$\begin{array}{l}\text { INTER- } \\
\text { MEDIO }\end{array}$} & \multicolumn{2}{|c|}{ ALTO } & \multicolumn{2}{|c|}{$\begin{array}{l}\text { MUY } \\
\text { ALTO }\end{array}$} \\
\hline 8 & Uso de verbos según el sujeto & 0 & 1 & 2 & 3 & 4 & 5 & 6 & 7 & 8 & 9 & 10 \\
\hline 9 & Tiempos verbales & 0 & 1 & 2 & 3 & 4 & 5 & 6 & 7 & 8 & 9 & 10 \\
\hline 10 & Orden de la estructura & 0 & 1 & 2 & 3 & 4 & 5 & 6 & 7 & 8 & 9 & 10 \\
\hline \multicolumn{2}{|c|}{ Vocabulario } & \multicolumn{2}{|c|}{$\begin{array}{l}\text { MUY } \\
\text { BAJO }\end{array}$} & \multicolumn{3}{|c|}{ BAJO } & \multicolumn{2}{|c|}{$\begin{array}{l}\text { INTER- } \\
\text { MEDIO }\end{array}$} & \multicolumn{2}{|c|}{ ALTO } & \multicolumn{2}{|c|}{$\begin{array}{l}\text { MUY } \\
\text { ALTO }\end{array}$} \\
\hline 11 & Usa vocabulario elaborado o básico & 0 & 1 & 2 & 3 & 4 & 5 & 6 & 7 & 8 & 9 & 10 \\
\hline 12 & Uso apropiado de las palabras & 0 & 1 & 2 & 3 & 4 & 5 & 6 & 7 & 8 & 9 & 10 \\
\hline
\end{tabular}

Nota: Tomado de Carvajal (2011) Tabla No.6 (p.57)

Una vez que la y el o la docente entrega el instrumento, le pide al estudiantado que autoevalúe su inglés. Se les explica que en el instrumento se utiliza una escala de 0 a 10, para que en cada ítem encierren en un círculo el número, el cual ellos piensan se encuentra su nivel; además, se le debe aclarar al estudiantado que no deben dejar ningún ítem en blanco y si tienen alguna duda la consulten a su profesor o profesora.

Para una mejor comprensión por parte del estudiantado que utilizará el "Instrumento de valoración de inglés", se presenta la definición de cada uno de los ítems que lo integran. 
Estrategias de comunicación: se refieren a la metodología utilizada por las y los aprendices cuando los mismos necesitan expresar un concepto o una idea utilizando un idioma extranjero.

Contacto visual: se refiere a la situación de dos individuos al mirarse a los ojos; es decir, es una forma de comunicación no verbal entre dos interlocutores, ambos se intercambian señales; por ejemplo, asentir con la cabeza.

Lenguaje corporal: este hace referencia especialmente a lo que las y los interlocutores quieren transmitir a través de un mensaje y demostrar congruencia entre lo que están informando de manera oral y corporal. A la vez es un componente de la comunicación que se tiene que tener presente, debido a que proporciona información sobre las emociones, reacciones de las y los individuos, tales como golpearse la frente ante un olvido, levantar una ceja al dudar de algo, levantar los hombros para indicar indiferencia, mecerse cuando se siente angustia, entre otros.

Gestos: estos se refieren a los gestos que forman parte de la comunicación no verbal, se hace con alguna parte del cuerpo humano cuando se quiere comunicar algo. En el lenguaje de los gestos, las y los individuos logran expresar sus sentimientos o sensaciones según sea su pensamiento, por ejemplo, de desprecio, de aprobación, de desacuerdo, etc. Muchas personas utilizan los gestos y lenguaje corporal cuando están hablando.

Monitoreo: este se refiere a la observación, la evaluación y al manejo que cada individuo tiene de sí mismo de acuerdo a su comportamiento. El mismo caso sucede cuando una persona se monitorea a través de la comunicación oral, porque evalúa y presta atención a lo que está tratando de comunicar.

Pronunciación: se refiere al acto o la manera de pronunciar las palabras; al articular en una forma prescrita se está indicando el sonido de una palabra por medio de símbolos fonéticos.

Consonantes: estas se refieren a los sonidos que emite la lengua, el cual es originado cuando se cierran o se estrechan todos los órganos del habla.

Vocales: se refiere al sonido que emite la lengua cuando se pronuncia un idioma.

Entonación: en ella se está haciendo mención al conjunto de tonos al unir sílabas en una frase, oración, mandato, etc. Son las variaciones de la altura que se produce al emitir un sonido, esto se debe a los cambios de tensión en las cuerdas vocales.

Gramática: se refiere al conjunto de reglas y relaciones que rigen las producciones de una lengua.

Uso de los verbos según el sujeto: este se refiere al uso correcto de los verbos al comunicarse, según sea el sujeto de la oración que se está comunicando.

Tiempos verbales: estos se refieren a los tiempos verbales que se utilizan para indicar el momento en que ocurre u ocurrió un evento o acción. 
Orden de la estructura: se refiere al orden estructural y la relación de las palabras dentro de una oración.

Vocabulario: este se refiere al conjunto de palabras que conoce y que utiliza un individuo.

Uso de vocabulario elaborado o básico: se refiere a la forma en que el o la docente evalúa los estudiantes al comunicarse oralmente; por ejemplo si el o la estudiante utiliza vocabulario básico; What's your name? My name is ______; o por el contrario utiliza un vocabulario más elevado como el uso de sinónimos de las palabras, adjetivos para referirse a lo que describe, uso de tiempos verbales, entre otros, dentro de un texto o comentario.

Uso apropiado de las palabras: se refiere a la evaluación que se le realiza al discente acerca de la coherencia y cohesión de las palabras dentro de una frase, un comentario, una oración, etc., al comunicarse oralmente.

Por otro lado, el o la docente puede interpretar los datos del estudiantado a través de la valoración del Marco Común Europeo, así calificará a sus estudiantes con las letras A (Usuario Básico), B (Usuario Independiente) y C (Usuario Competente) pág.24.

Usuario Básico A1: Comprender y utilizar expresiones cotidianas y frases sencillas destinadas a satisfacer necesidades de tipo inmediato. Además puede introducir, pedir y dar información personal básica del lugar donde vive, la gente que conoce y las cosas que tiene. Puede relacionarse de forma elemental siempre que su interlocutor hable despacio y con claridad y esté dispuesto a cooperar.

Usuario Básico A2: Comprender frases y expresiones de uso frecuente relacionadas con áreas de relevancia inmediata (información básica sobre sí mismo y su familia, compras, lugares de residencia, empleo). Puede comunicarse en tareas simples y cotidianas que no requieran más que intercambios sencillos y directos de información sobre cuestiones conocidas o habituales. Sabe describir en términos sencillos aspectos de su entorno inmediato y asuntos en las áreas de necesidad inmediata.

Usuario Independiente B1: Comprender los puntos principales de una conversación clara sobre asuntos cotidianos que tienen lugar en el trabajo, la escuela, el ocio, etc. Puede hacer frente a la mayoría de las situaciones que pueden surgir durante un viaje por zonas donde se utiliza el inglés. Puede producir textos sencillos y coherentes sobre temas que le son familiares o de interés personal. Puede describir experiencias, acontecimientos, deseos y aspiraciones, así como dar la razón y explicaciones para opiniones y planes.

Usuario Independiente B2: Entender las ideas principales de textos complejos que traten de temas tanto concretos como abstractos, incluyendo discusiones técnicas en su campo de especialización. Puede relacionarse con hablantes nativos sin esfuerzo de ambas partes. Puede producir textos claros y detallados sobre temas diversos así como defender un punto de vista sobre un tema, exponiendo las ventajas y los inconvenientes 
de varias opciones.

Usuario Competente C1: Comprender una amplia variedad de textos extensos y con ellos sentidos implícitos. Puede expresarse espontáneamente con fluidez y sin muestras muy evidentes de esfuerzo al expresarse. Puede utilizar el lenguaje con flexibilidad y eficacia para fines sociales, académicos y profesionales. Puede producir textos claros, bien estructurados y detallados sobre temas complejos, mostrando un uso correcto de los mecanismos de organización, articulación y cohesión del texto.

Usuario Competente C2: Comprender con facilidad prácticamente todo lo que oye o lee. Puede resumir información de diversas fuentes orales y escritas, reconstruir argumentos y relatos en una presentación coherente. Puede expresarse espontáneamente, con gran fluidez y precisión, permite diferenciar pequeños matices de significado incluso en situaciones de mayor complejidad.

\subsection{Indicador para determinar el nivel real de inglés de los estudiantes en la enseñanza del inglés en secundaria}

Cuando el estudiantado ha terminado de autoevaluarse, con el instrumento anterior, el o la docente recoge esos instrumentos y procede a insertar los datos en cada una de las "pestañas" del instrumento llamado "Indicador para determinar el nivel real de inglés de los estudiantes de los colegios públicos de Costa Rica", al finalizar, este le dará a conocer el nivel real en que se encuentra tanto el o la estudiante individualmente como el grupo en general. Asimismo, el instrumento le ofrece al docente, la información respecto a la posición tipo "semáforo", en que se encuentra el o la estudiante y el grupo en general, tomando en cuenta la escala de 0 a 10 . En esa escala se interpreta que, de 0 a 10 en donde los valores muy bajos ( 0 y 1 ), los bajos (2, 3 y 4) el color del "semáforo" indicará rojo, niveles intermedios (5 y 6) será de color amarillo, los valores altos (7 y 8) y muy altos (9 y 10) estos se cambian al color verde. 
Tabla N.2. Indicador para determinar el nivel de inglés de los estudiantes en secundaria

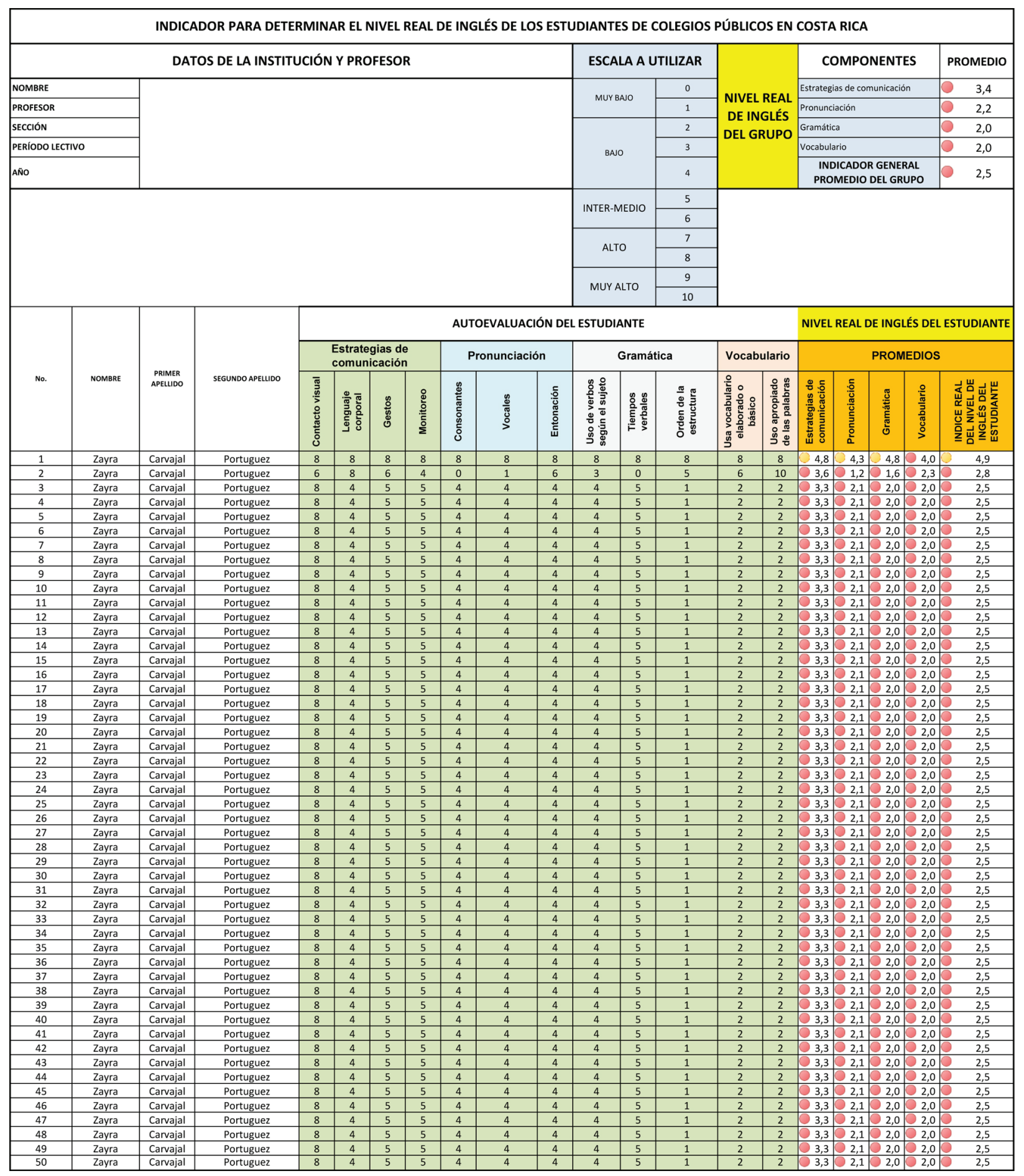

Nota: Tomado de Carvajal (2011) Tabla No.15 (p. 102) 
Una vez obtenido el nivel de inglés del grupo, se planean las actividades que va a llevar a cabo el o la docente con sus estudiantes, tanto dentro como fuera del aula. Después del desarrollo de las actividades que cada docente logró hacer en la semana, quincena, mes o trimestre, ese tiempo lo estipula el o la docente, se debe diagnosticar nuevamente a las y los alumnos con el instrumento de valoración de inglés.

Por consiguiente, se le pide a las y los alumnos que autoevalúen su nivel de inglés, luego se introducen los datos en el instrumento que utilizó el o la docente al principio; así, el educador podrá conocer el nivel de inglés que cada estudiante logró después de realizar las actividades.

Lo ideal es que el o la docente mantenga el registro de cada una de las evaluaciones, para que pueda valorar si el o la estudiante está aumentando su nivel de inglés o por el contrario necesita que se le estimule aún más.

Además, como parte de la propuesta, se le sugiere a las y los docentes llevar a cabo experiencias o actividades de aprendizaje tanto individual como grupal, ya que en ocasiones, el estudiantado necesita sentirse cómodo para poder participar, sobre todo si se trata de participar oralmente.

\section{Planeamiento de actividades para cada una de las habilidades del inglés}

Como parte de esta propuesta, se ofrecen los planeamientos con actividades en cada una de las habilidades del idioma inglés, según el Programa de Estudio del Ministerio de Educación Pública del ciclo diversificado.

Los planeamientos cuentan con el objetivo específico, las actividades, el tiempo aproximado que necesita el o la docente para llevar a cabo cada actividad y el tipo de evaluación que se puede realizar por actividad. Se aclara que en la columna de contenidos se deja abierto para que el o la docente coloque los que crea que podrá abarcar de acuerdo con el tema que esté trabajando, pues este cambiará de acuerdo con cada nivel académico.

Por otro lado, se sugiere que las actividades propuestas, se lleven a cabo a través de todo el año, según lo permita cada tema de estudio; además, se pueden realizar tanto dentro como fuera del aula. Como ya se ha mencionado, se le sugiere al docente, que una vez llevadas a cabo las actividades, vuelva a utilizar el instrumento de inglés en sus estudiantes, para que nuevamente los diagnostique. 


\section{Tabla 3: Algunas experiencias o actividades de aprendizaje en la habilidad de Listening}

\begin{tabular}{|c|c|c|c|}
\hline Objetivo & Actividades & $\begin{array}{l}\text { Tiempo } \\
\text { aproximado }\end{array}$ & Evaluación \\
\hline $\begin{array}{l}\text { Identificar nuevo vocabulario } \\
\text { a través del contexto dado. }\end{array}$ & $\begin{array}{l}\text { Escuchar una canción a través de un } \\
\text { disco compacto (CD). }\end{array}$ & 45 minutos & $\begin{array}{l}\text { Comprendió el tema a tratar a pesar } \\
\text { de contener nuevo vocabulario. }\end{array}$ \\
\hline $\begin{array}{l}\text { Identificar el tema principal } \\
\text { del cuento o historieta. }\end{array}$ & $\begin{array}{l}\text { Escuchar cuentos cortos por medio } \\
\text { de la lectura hecha por un hablante } \\
\text { nativo. }\end{array}$ & 40 minutos & $\begin{array}{l}\text { Comentó el tema principal de la } \\
\text { lectura del cuento o historieta hecha } \\
\text { por un hablante nativo. }\end{array}$ \\
\hline $\begin{array}{l}\text { Contestar preguntas cortas } \\
\text { acerca del tema en estudio. }\end{array}$ & $\begin{array}{l}\text { Escuchar conversaciones cortas a } \\
\text { través de un CD. }\end{array}$ & 45 minutos & $\begin{array}{l}\text { Comprendió lo escuchado y } \\
\text { respondió preguntas sobre el tema } \\
\text { expuesto. }\end{array}$ \\
\hline $\begin{array}{l}\text { Predecir el acontecimiento } \\
\text { siguiente. }\end{array}$ & Narración de cuentos. & 50 minutos & $\begin{array}{l}\text { Predijo satisfactoriamente el } \\
\text { siguiente acontecimiento, después } \\
\text { de lo narrado por el docente. }\end{array}$ \\
\hline $\begin{array}{l}\text { Comprender el tema principal } \\
\text { de una canción. }\end{array}$ & Escuchar una canción. & 25 minutos & $\begin{array}{l}\text { Comentó cuál era el tema a tratar } \\
\text { en la canción que escuchó en el CD. }\end{array}$ \\
\hline Realizar una entrevista corta. & $\begin{array}{l}\text { Hacer preguntas para formar una } \\
\text { entrevista corta a un hablante nativo. }\end{array}$ & 15 minutos & $\begin{array}{l}\text { Realizó preguntas con fluidez y } \\
\text { comprendió las respuestas dadas } \\
\text { por el hablante nativo. }\end{array}$ \\
\hline Mantener una conversación. & $\begin{array}{l}\text { Invitar a un o una docente en inglés } \\
\text { de otro grupo para conversar en la } \\
\text { clase sobre cualquier tema. }\end{array}$ & 10 minutos & $\begin{array}{l}\text { Realizó y contestó preguntas } \\
\text { al docente o al invitado sin } \\
\text { complicaciones. }\end{array}$ \\
\hline Hablar de un día festivo. & $\begin{array}{l}\text { Realizar una mesa redonda en la } \\
\text { clase sobre un día festivo. }\end{array}$ & 10 minutos & $\begin{array}{l}\text { Conversó en la clase fluidamente } \\
\text { sobre el día festivo en cuestión. }\end{array}$ \\
\hline Identificar la noticia. & $\begin{array}{l}\text { Comentar lo escuchado en la radio } \\
\text { o televisión sobre una noticia } \\
\text { importante. }\end{array}$ & 10 minutos & $\begin{array}{l}\text { Resumió y comentó en la clase la } \\
\text { noticia importante que escuchó en } \\
\text { la TV o en la radio. }\end{array}$ \\
\hline $\begin{array}{l}\text { Hablar sobre el tema de } \\
\text { conversación que se lleva a } \\
\text { cabo entre hablantes nativos. }\end{array}$ & $\begin{array}{l}\text { Por medio de un } \mathrm{CD} \text {, escuchar la } \\
\text { conversación entre hablantes nativos } \\
\text { y comentar de qué trataba. }\end{array}$ & 25 minutos & $\begin{array}{l}\text { Comentó con precisión el tema } \\
\text { de conversación entre hablantes } \\
\text { nativos. }\end{array}$ \\
\hline $\begin{array}{l}\text { Contestar preguntas a través } \\
\text { de una llamada telefónica. }\end{array}$ & $\begin{array}{l}\text { Participar de una pequeña entrevista } \\
\text { telefónica que le hace el o la docente. }\end{array}$ & 10 minutos & $\begin{array}{l}\text { Respondió correctamente las } \\
\text { preguntas hechas. }\end{array}$ \\
\hline Seguir instrucciones. & Crear una figura, diseño, dibujo, etc. & 8 minutos & $\begin{array}{l}\text { Dibujó correctamente lo que se le } \\
\text { pidió a través de las instrucciones } \\
\text { dadas. }\end{array}$ \\
\hline Leer en voz alta. & $\begin{array}{l}\text { Escuchar la narración de cualquier } \\
\text { historia a través de la lectura que } \\
\text { realiza el hablante nativo invitado o } \\
\text { al docente. }\end{array}$ & 5 minutos & $\begin{array}{l}\text { Comentó con fluidez sobre el tema } \\
\text { de la historia leída por el docente o } \\
\text { hablante nativo. }\end{array}$ \\
\hline
\end{tabular}

Nota: Tomado de Carvajal (2011) Tabla No.5.5.1 (pp. 108, 109, 110) 


\section{Tabla N. 4. Algunas experiencias o actividades de aprendizaje en la habilidad de Speaking}

\begin{tabular}{|c|c|c|c|}
\hline Objetivo & Actividades & $\begin{array}{l}\text { Tiempo } \\
\text { aproximado }\end{array}$ & Evaluación \\
\hline $\begin{array}{l}\text { Escribir diálogos y } \\
\text { actuarlos. }\end{array}$ & $\begin{array}{l}\text { Actuar ante los compañeros } \\
\text { y las compañeras } \\
\text { utilizando diálogos que } \\
\text { ellos mismos han escrito. }\end{array}$ & 5 minutos & $\begin{array}{l}\text { Expresaron de manera espontánea } \\
\text { diálogos producidos por ellos } \\
\text { mismos. }\end{array}$ \\
\hline $\begin{array}{l}\text { Representar escenas } \\
\text { de obras de teatro. }\end{array}$ & $\begin{array}{l}\text { Actuar escenas de obras } \\
\text { de teatro. }\end{array}$ & 15 minutos & $\begin{array}{l}\text { Utilizó el lenguaje con flexibilidad y } \\
\text { eficiencia en las escenas actuadas. }\end{array}$ \\
\hline $\begin{array}{l}\text { Planificar un } \\
\text { cuestionario. }\end{array}$ & $\begin{array}{l}\text { Contestar el cuestionario } \\
\text { oral. }\end{array}$ & 10 minutos & $\begin{array}{l}\text { Respondió de manera estructurada } \\
\text { y coherente el cuestionario. }\end{array}$ \\
\hline $\begin{array}{l}\text { Simular roles de la } \\
\text { vida real. }\end{array}$ & $\begin{array}{l}\text { Compartir encuentros de } \\
\text { la vida real. }\end{array}$ & 15 minutos & $\begin{array}{l}\text { Simuló un encuentro de la vida } \\
\text { real (en la cabina de una avión, } \\
\text { un restaurante) junto con otros } \\
\text { compañeros y compañeras. }\end{array}$ \\
\hline $\begin{array}{l}\text { Simular roles de la } \\
\text { vida real. }\end{array}$ & $\begin{array}{l}\text { Simular ser personas } \\
\text { importantes que serán } \\
\text { invitadas y entrevistadas } \\
\text { en la clase. }\end{array}$ & 20 minutos & $\begin{array}{l}\text { Simuló el ser una persona importante } \\
\text { de la vida real, quien debió responder } \\
\text { preguntas tales como quién es, qué } \\
\text { piensa de, qué siente, entre otras. }\end{array}$ \\
\hline
\end{tabular}

Nota: Tomado de Carvajal (2011) Tabla No.5.5.2 ( pp. 111, 112)

\section{Tabla 5. Algunas experiencias o actividades de aprendizaje en la habilidad de Reading}

\begin{tabular}{|c|c|c|c|}
\hline Objetivo & Actividades & $\begin{array}{l}\text { Tiempo } \\
\text { aproximado }\end{array}$ & Evaluación \\
\hline $\begin{array}{l}\text { Predecir el } \\
\text { contenido de un } \\
\text { texto. }\end{array}$ & $\begin{array}{l}\text { Predecir el contenido de un texto a } \\
\text { través de algunas pistas tentadoras que } \\
\text { se les da. }\end{array}$ & 10 minutos & $\begin{array}{l}\text { Predijo correctamente } \\
\text { el contenido del texto } \\
\text { utilizando las pistas } \\
\text { dadas. }\end{array}$ \\
\hline $\begin{array}{l}\text { Comprender una } \\
\text { lectura. }\end{array}$ & $\begin{array}{l}\text { Leer un texto por ellos mismos y } \\
\text { contestar preguntas detalladas de } \\
\text { comprensión. }\end{array}$ & 20 minutos & $\begin{array}{l}\text { Comprendió el texto y } \\
\text { contestó las preguntas } \\
\text { sin mucho esfuerzo. }\end{array}$ \\
\hline $\begin{array}{l}\text { Relacionar nuevas } \\
\text { palabras del } \\
\text { texto con sus } \\
\text { definiciones. }\end{array}$ & $\begin{array}{l}\text { Relacionar las nuevas palabras del } \\
\text { texto con sus definiciones utilizando el } \\
\text { contexto que le ofrece la lectura. }\end{array}$ & 20 minutos & $\begin{array}{l}\text { Relacionó } \\
\text { correctamente las } \\
\text { nuevas palabras } \\
\text { del texto con sus } \\
\text { definiciones. } \\
\end{array}$ \\
\hline
\end{tabular}




\begin{tabular}{llll}
\hline Objetivo & Actividades & $\begin{array}{l}\text { Tiempo } \\
\text { aproximado }\end{array}$ & Evaluación \\
\hline $\begin{array}{l}\text { Completar un } \\
\text { cuadro después de } \\
\text { leer una historia. }\end{array}$ & $\begin{array}{l}\text { Completar un cuadro con información } \\
\text { que se le solicita acerca de la historia } \\
\text { leída anticipadamente. }\end{array}$ & 15 minutos & $\begin{array}{l}\text { Produjo en un cuadro } \\
\text { información detallada } \\
\text { relacionada con la } \\
\text { historia narrada. }\end{array}$ \\
$\begin{array}{l}\text { Contestar } \\
\text { preguntas } \\
\text { específicas de un } \\
\text { texto. }\end{array}$ & $\begin{array}{l}\text { Contestar preguntas específicas de un } \\
\text { texto dado. }\end{array}$ & 20 minutos & $\begin{array}{l}\text { Contaramente } \\
\text { las preguntas. }\end{array}$ \\
& & & \\
$\begin{array}{l}\text { Predecir el } \\
\text { contenido de una } \\
\text { imagen. }\end{array}$ & $\begin{array}{l}\text { Predecir el contenido de una imagen a } \\
\text { través de algunas pistas que se les da. }\end{array}$ & 10 minutos & $\begin{array}{l}\text { Predijo correctamente } \\
\text { la imagen que le } \\
\text { escribieron. }\end{array}$ \\
\hline
\end{tabular}

Nota:Tomado de Carvajal (2011) Tabla No.5.5.3 (pp.113, 114)

\section{Tabla 6. Algunas experiencias o actividades de aprendizaje en la habilidad de Writing}

\begin{tabular}{|c|c|c|c|}
\hline Objetivo & Actividades & $\begin{array}{l}\text { Tiempo } \\
\text { aproximado }\end{array}$ & Evaluación \\
\hline $\begin{array}{l}\text { Desempeñar un } \\
\text { papel central para } \\
\text { crear un texto. }\end{array}$ & $\begin{array}{l}\text { Crear un texto que sea para } \\
\text { la persona que desempeña el } \\
\text { papel central. }\end{array}$ & 15 minutos & $\begin{array}{l}\text { Escribió con facilidad y coherencia el } \\
\text { texto del personaje central. }\end{array}$ \\
\hline $\begin{array}{l}\text { Redactar textos } \\
\text { claros y detallados } \\
\text { sobre un tema. }\end{array}$ & $\begin{array}{l}\text { Redactar a partir de un tema } \\
\text { asignado textos detallados y } \\
\text { claros. }\end{array}$ & 20 minutos & $\begin{array}{l}\text { Produjo textos claros y detallados } \\
\text { sobre el tema en cuestión. }\end{array}$ \\
\hline $\begin{array}{l}\text { Estructurar } \\
\text { información sobre } \\
\text { un tema. }\end{array}$ & $\begin{array}{l}\text { Organizar correctamente la } \\
\text { información de un tema. }\end{array}$ & 10 minutos & $\begin{array}{l}\text { Utilizó correctamente los } \\
\text { mecanismos de organización, } \\
\text { articulación, etc. al estructurar } \\
\text { información. }\end{array}$ \\
\hline $\begin{array}{l}\text { Generar escritura } \\
\text { creativa. }\end{array}$ & $\begin{array}{l}\text { Desarrollar escritura creativa } \\
\text { a través de poesía, un cuento, } \\
\text { una obra de teatro, etc. }\end{array}$ & 25 minutos & $\begin{array}{l}\text { Expresó de manera espontánea y } \\
\text { fluida su creatividad por medio de } \\
\text { una poesía, un cuento, una obra de } \\
\text { teatro, etc. }\end{array}$ \\
\hline $\begin{array}{l}\text { Redactar el final } \\
\text { de la historia. }\end{array}$ & $\begin{array}{l}\text { Escuchar una historia y mirar } \\
\text { las fotos de la misma después } \\
\text { el estudiantado debe escribir el } \\
\text { posible final de la historia. }\end{array}$ & 5 minutos & $\begin{array}{l}\text { Redactó párrafos claros y detallados } \\
\text { sobre el posible final de la historia. }\end{array}$ \\
\hline
\end{tabular}

Nota: Tomado de Carvajal (2011) Tabla No.5.5.4 (pp. 115, 116, 117) 


\subsection{Conclusiones}

El papel del alumno o alumna no es estático como simple receptor de los conocimientos, sino que él o ella participa activamente en su aprendizaje, discutiendo y practicando el idioma inglés en situaciones propuestas por el o la docente, pero en una situación más real, esto con el propósito de que más tarde el o la estudiante pueda tomar ventaja de lo aprendido y lo utilice en su vida cotidiana.

La intención de la propuesta es que sea un punto de apoyo para las y los docentes que tienen a cargo la enseñanza y aprendizaje del idioma inglés de secundaria en el sistema educativo costarricense. Es trascendental resaltar que las actividades propuestas se basan en cuatro habilidades del inglés, tal y como lo plantea el Programa de Estudio en la Enseñanza del Inglés diversificada del Ministerio de Educación Pública de Costa Rica.

En consecuencia, se espera que las sugerencias sean útiles respecto a las experiencias o actividades de aprendizaje, como parte del planeamiento didáctico del docente para poder lograr los objetivos propuestos en el programa de estudios.

\section{Referencias Bibliográficas}

Bello, P. (1990). Didáctica de las segundas lenguas. Madrid. Santillana.

Brown, H. D. (1994). Principles of Language Learning and Teaching. [Principios del aprendizaje de idiomas y de la enseñanza] United States. Prentice Hall Regents.

Brumfit, Ch y Johnson, K. (Ed.) (1987). The Communicative Approach to Language Teaching. [El enfoque comunicativo de la enseñanza de idiomas] Nueva York. Oxford University Press.

Carvajal, Z. (2011). Lineamientos curriculares en la enseñanza de inglés en secundaria, basados en el enfoque comunicativo. Tesis de Maestría, Universidad de Costa Rica. San José, Costa Rica

Celce-Murcia, M. (Ed.) (1991). Teaching English as a Second or Foreign Language. [Enseñanza del Inglés como segunda lengua o lengua extranjera] Estados Unidos. Heinle \& Heinle Publishers.

Cook, T. y Reichardt, Ch. (1997). Métodos Cualitativos y Cuantitativos en Investigación. Madrid, España. Ediciones Morata.

Dlugosz, D. (2000). Rethinking the role of reading in teaching a foreign Language to Young Learners. [Repensando el papel de la lectura en la enseñanza de un idioma extranjero para estudiantes jóvenes]. ELT Journal. 54/3. July, 2000. Pág.286

Escudero, J. (Ed.) (1999). Diseño, desarrollo e innovación del currículum. España. Editorial Síntesis.

European Committee. (2001). Common European Framework of Reference for Languages: 
Learning, Teaching, Assessment. [Marco Común Europeo de Referencia para las lenguas: aprendizaje, enseñanza, evaluación]. Council for Cultural Cooperation Education Committee Language Policy Division, Strasbourg. Cambridge University Press.

Garibay, B. (2002). Experiencias de aprendizaje: Educación Siglo XXI. Para que mis alumnos aprendan. Una guía de acción. Universidad Autónoma del Carmen. México.

Gimeno, J. (2007). El Currículum: una reflexión sobre la práctica. Madrid, España: Morata.

Gimeno, J. (2010). Saberes e incertidumbres sobre el currículum. Madrid, España: Morata.

Harmer, J. (2007). How to teach English. [Cómo enseñar inglés]. England. Longman

Harmer, J. (2011). The Practice of English Language Teaching. [La práctica de la Enseñanza del idioma Inglés]. England. Longman

Hernández, P. (1998). Diseñar y Enseñar. Teoría y técnicas de la programación y del proyecto docente. España: Narcea.

Littlewood, W. (1992). La enseñanza de la comunicación oral. Un marco metodológico. Barcelona. Paidós.

Mackey, W. (1969). Language Teaching Analysis. [Análisis de la Enseñanza de Idiomas]. Gran Bretaña. Longmans.

Ministerio de Educación Pública. (2005). Programa de Estudio de Educación DiversificadaInglés. San José, Costa Rica.

Posner, G. (2004). Análisis del Currículo. México, D.F. Mc Graw-Hill. 